\title{
A VERMILION COLOR FROM URANIUM*
}

By Charles F. Binns and Frobisher lyttle

Not very much appears to have been written upon the subject of uranium oxide as a colorant, though the production of uranium blacks under reduction, and yellows under oxidation, has long been practised, especially by porcelain decorators.

Three papers have been published in the Transactions of the Society, one by Riddle in Volume VIII, the second by Minton in Volume IX, and the third by Koener in Volume X, the last referring especially to uranium bismuth crystals.

Riddle quotes Cunninghame in "The Art of Enamelling on Metals" to the effect that the yellow oxide of uranium "has a feeble coloring power," a statement which Riddle controverts by showing that, fused with lead compounds, uranium produces a rich orange. Minton, in discussing Riddle's contribution, confirms this statement and further points out the variations which accrue when different oxides of uranium are used.

The present experiment was inspired by the accidental development of a peculiarly rich vermilion red almost a scarlet.

The problem undertaken was the production of greens for terra cotta under open kiln conditions, without the use of copper or chromium as colorants. A triangle was plotted, of which the angles were a cobalt blue, a uranium yellow, and a colorless glaze containing zinc oxide. The base of the triangle, of which one extremity was the uranium color, and the other the zinc glaze, afforded several examples of a rather vivid orange, and it was decided to pursue this line of investigation.

Two glazes were made, corresponding to the formulas:

vo

$$
\left.\begin{array}{l}
0.80 \mathrm{PbO} \\
0.12 \mathrm{~K}_{2} \mathrm{O} \\
0.07 \mathrm{ZnO}
\end{array}\right\} 0.12 \mathrm{Al}_{2} \mathrm{O}_{3}\left\{\begin{array}{l}
1.33 \mathrm{SiO}_{2} \\
\end{array}\right.
$$

To the batch was added 20 per cent commercial yellow oxide of uranium (sodium uranate) and the whole was fritted.

${ }^{*}$ Received Feb. 27, 1920. 
This corresponds approximately to the mixture:

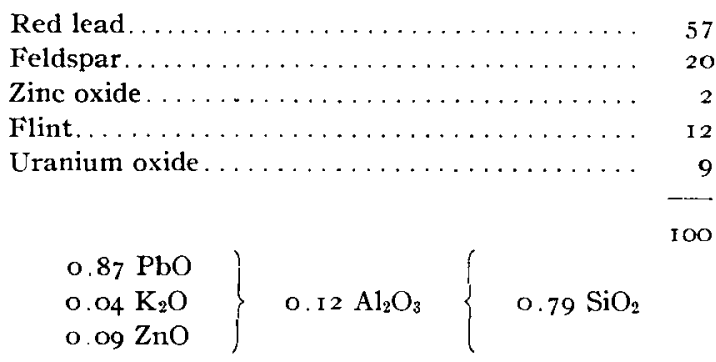

To this was added 37 per cent of the same uranium oxide and the whole was fritted, except the necessary amount of clay.

Glaze No. I was the bright vermilion color, but this did not appear in No. 2, which seems to indicate that the amount of uranium present must not greatly vary.

The texture of the glaze has not yet been fully investigated. Probably the absence of luster is due to insufficient temperature. These glazes were fired in closed saggers and not in the open kiln, the heat treatment being cone o4 for VO and cone o2 for VI.

Some difficulty has been experienced in protecting the uranium oxide from reducing influences, but with complete oxidation these vermilion colors seem to be a commercial possibility.

New York State School, of Chayworking and Ceramics ALFRED, NEW YORK

Norrce.-Further discussion of this subject is solicited. All communications should be senl to the Editor. 